\title{
Application of Quality Assurance Strategies in Diagnostics and Clinical Support Services in Iranian Hospitals
}

\author{
Asgar Aghaei Hashjin ${ }^{1,2 *}$, Dionne Kringos ${ }^{1}$, Hamid Ravaghi ${ }^{2}$, Jila Manoochehri ${ }^{3}$, Hassan Abolghasem Gorji ${ }^{2}$, \\ Niek S. Klazinga ${ }^{1}$
}

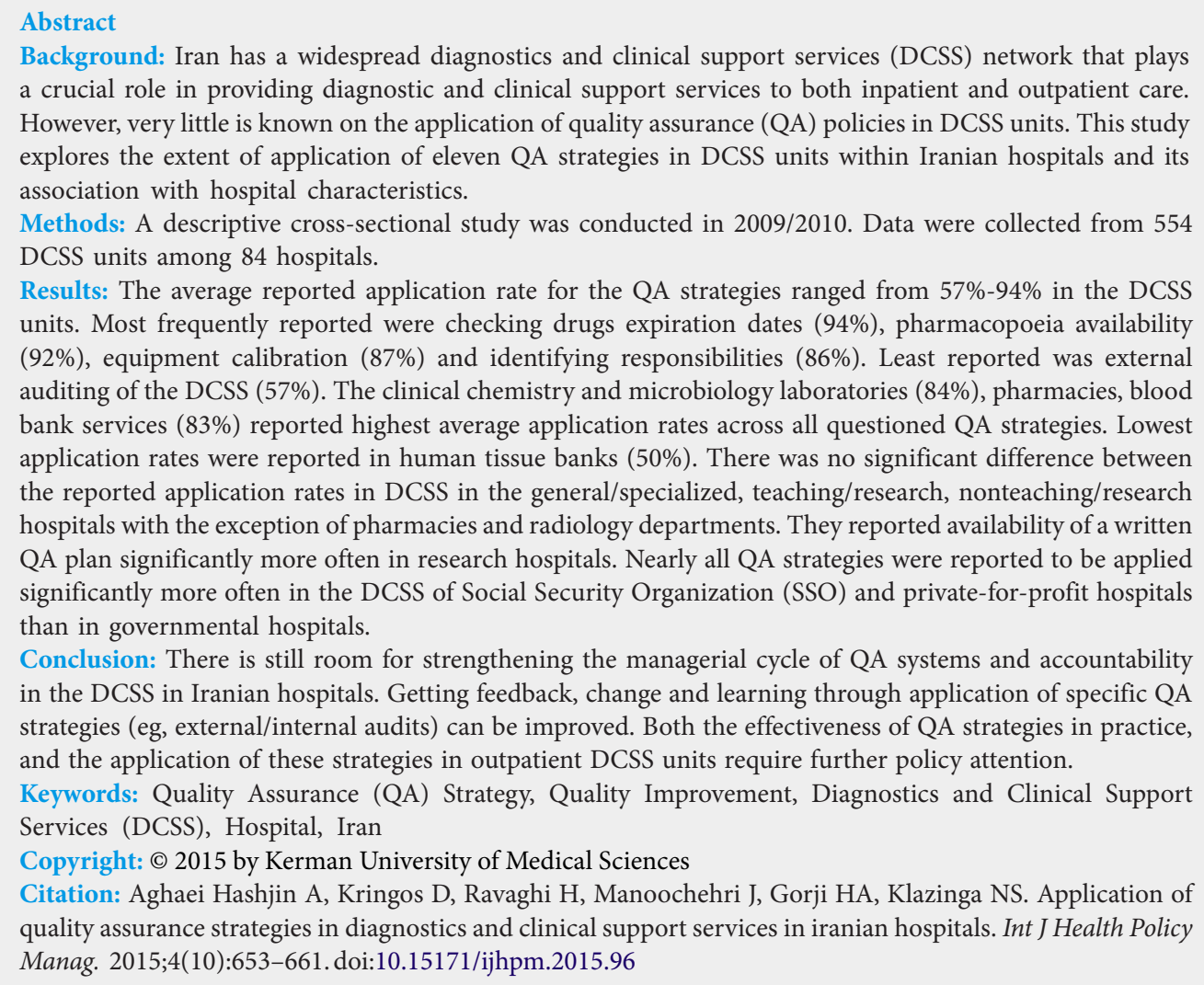

Background: Iran has a widespread diagnostics and clinical support services (DCSS) network that plays a crucial role in providing diagnostic and clinical support services to both inpatient and outpatient care. However, very little is known on the application of quality assurance (QA) policies in DCSS units. This study explores the extent of application of eleven QA strategies in DCSS units within Iranian hospitals and its association with hospital characteristics.

Methods: A descriptive cross-sectional study was conducted in 2009/2010. Data were collected from 554 DCSS units among 84 hospitals.

Results: The average reported application rate for the QA strategies ranged from 57\%-94\% in the DCSS units. Most frequently reported were checking drugs expiration dates (94\%), pharmacopoeia availability (92\%), equipment calibration (87\%) and identifying responsibilities (86\%). Least reported was external auditing of the DCSS (57\%). The clinical chemistry and microbiology laboratories (84\%), pharmacies, blood bank services (83\%) reported highest average application rates across all questioned QA strategies. Lowest application rates were reported in human tissue banks (50\%). There was no significant difference between the reported application rates in DCSS in the general/specialized, teaching/research, nonteaching/research hospitals with the exception of pharmacies and radiology departments. They reported availability of a written QA plan significantly more often in research hospitals. Nearly all QA strategies were reported to be applied significantly more often in the DCSS of Social Security Organization (SSO) and private-for-profit hospitals than in governmental hospitals.

Conclusion: There is still room for strengthening the managerial cycle of QA systems and accountability in the DCSS in Iranian hospitals. Getting feedback, change and learning through application of specific QA strategies (eg, external/internal audits) can be improved. Both the effectiveness of QA strategies in practice, and the application of these strategies in outpatient DCSS units require further policy attention.

Keywords: Quality Assurance (QA) Strategy, Quality Improvement, Diagnostics and Clinical Support Services (DCSS), Hospital, Iran

Copyright: (C) 2015 by Kerman University of Medical Sciences

Citation: Aghaei Hashjin A, Kringos D, Ravaghi H, Manoochehri J, Gorji HA, Klazinga NS. Application of quality assurance strategies in diagnostics and clinical support services in iranian hospitals. Int J Health Policy Manag. 2015;4(10):653-661. doi:10.15171/ijhpm.2015.96

\section{Article History:}

Received: 14 January 2015

Accepted: 11 May 2015

ePublished: 20 May 2015

\section{Key Messages}

Implications for policy makers

- More attention at policy level is needed for the application of quality assurance (QA) strategies in both inpatient and outpatient diagnostics and clinical support services (DCSS) units across different organizational affiliations to increase the compliance with national QA requirements.

- There is room for strengthening the managerial cycle of QA systems in DCSS units by moving from formalization and standardization towards feedback and improvement of QA strategies.

- More reliable statistics in medical and diagnostic errors are needed to better evaluate, and improve the effectiveness of current QA strategies in DCSS units.

\section{Implications for public}

The general public should be able to trust that the diagnostics tests and clinical support services they receive are appropriate, accurate and of highquality. On the other hand, the government should be able to guarantee a minimum level of quality of diagnostic and clinical support services for the public in all diagnostics and clinical support services (DCSS) units both in outpatient and inpatient units and regardless their organizational affiliations. 


\section{Background}

Accurate diagnostic tests and high-quality appropriate clinical support services are essential in the diagnostic process and treatment of patients. ${ }^{1}$ Currently, the provision of most clinical services in hospitals is directly linked to their diagnostics and clinical support services (DCSS). Almost all patients receive services by the DCSS during their hospitalization. ${ }^{2}$ Failure to provide these services with a sufficient quality level can result in unjustified treatment, which may harm patients..$^{3-8}$ Although it is difficult to find out the exact statistics of the diagnostic and medical errors, lethal diagnostic errors have been estimated through the Global Trigger Tool to affect 40000-80000 people per year in the United States. ${ }^{9}$

Given the critical role of DCSS, there has recently been an increased awareness among patients, policy-makers and healthcare managers about the need for quality assurance (QA) in DCSS. ${ }^{1,10}$ QA in DCSS comprises a series of critical activities that can influence the appropriateness (ie, clinical effectiveness) of services to patients and their health and clinical outcomes. Examples of strategies to ensure the quality of care in DCSS units include quality control, improving accuracy of the diagnostics, external and internal quality assessment and audit, identifying responsibilities, standardization through guidelines and standards, monitoring of key processes and equipment calibration. ${ }^{10,11}$

Despite the increased focus on ensuring quality in the DCSS particularly in developed countries, clinical care in some (often middle- and low-income) countries is lacking QA and regulatory controls. ${ }^{1,12}$ Iran is such a country of which very little is known on the application of QA strategies in DCSS units.

Iran has a widespread DCSS network that plays a crucial role in providing diagnostic and clinical support services to both inpatient and outpatient care. The network consists of more than 4000 public and private clinical laboratories and thousands of diagnostic radiology units and pharmacies. ${ }^{13,14}$ However, there are limited numbers of specialized DCSS units (eg, human tissue bank or nuclear medicine). Based on the Iranian National Health Act (1955), all hospitals are obliged to have a laboratory, diagnostic radiology and pharmacy in place. According to this Act, all DCSS units both inside and outside of hospitals should obey a set of standards and be licensed to practice. ${ }^{15,16}$ The government together with the relevant specialty associations (eg, radiologist association) controls the quality of services in these units. ${ }^{17}$ The health reference laboratory (HRL) and general directorate of laboratory affairs (GDLA) in each medical sciences university control the quality of diagnostic tests, check compliance with safety guidelines and standards for all clinical laboratories. The Iranian Blood Transfusion Organization (IBTO) provides guidelines and standards for blood banks and transfusion services across the country. ${ }^{18}$

More recently, there has been an increasing interest among DCSS units to get International Organization for Standardization (ISO) certification, in particular among private DCSS. To obtain this, the DCSS units have to comply with the basic requirements for acceptable levels of quality and performance, undergo planned and unplanned inspections. Furthermore, the DCSS that are located in hospitals should undergo a governmental evaluation program at least once a year. ${ }^{19}$

Despite the regulatory importance given to the quality in DCSS units, to date very few studies have explored the actual application of QA strategies in DCSS units in practice. The majority of the existing studies have focused only on the quality control and accuracy of diagnostic (especially laboratory) tests. ${ }^{20,21}$ Insight in the application of QA strategies can provide a view on the strategies that can guarantee and ensure the quality of DCSS services. This study therefore aims to describe the extent of application of QA strategies for ensuring the quality of services provided by DCSS units, and explore how the level of application is associated with the characteristics of hospitals in which the DCSS units are located, in particular the teaching/research and ownership status and the hospital performance grade.

\section{Methods}

This is a descriptive cross-sectional study conducted from October 2009 through February 2010 among 554 DCSS units of 84 hospitals in Iran. Data were collected through a questionnaire that consisted of 11 close-ended questions covering main QA strategies related to the DCSS units. The explored strategies were: $(i)$ the identification and (formal) division of responsibilities, (ii) the presence of a written QA plan, (iii) the presence of written guidelines and standards for the main tests or treatment, (iv) monitoring of key processes and actions, $(v)$ systematic evaluation of collected data, $(v i)$ inspection, calibration and maintenance of equipment on a regular basis, and ( $v i$ ii/viii) periodic internal/external audit of the service. The strategies are categorized in 4 main groups representing the managerial cycle for QA; (1) Identification and documentation of responsibilities, (2) Availability of a QA plan, guidelines and standards, (3) Monitoring and systematic evaluation of services, and (4) Inspection and audit of services. In case of pharmacy units, we also explored three specific additional QA strategies including checking drugs and medical disposals' expiration date, compliance with the national pharmacopoeia, and presence and use of a computerized prescription system (CPS). The questionnaire was distributed among the responsible persons for QA activities at the DCSS units, including head of department, general supervisor, leader/manager or technical supervisor.

\section{The Questionnaire}

The questions included in the questionnaire were derived from the Methods of Assessing Response to Quality Improvement Strategies (MARQuIS) project's questionnaire, which was developed to assess the application of different quality strategies in hospitals in European Union (EU) countries. $^{22,23}$ This was a validated questionnaire which was implemented across Europe, and could be used to compare the results of our study. The questions were first translated from English to Farsi and adapted for Iranian hospitals by the authors. After verifying the content of the translated and adapted questionnaire, it was piloted in 5 hospitals (including 3 public governmental, 1 private-for-profit and 1 Social Security Organization [SSO] hospital). Necessary changes and further improvements were made based on the responses received from the pilot hospitals. Each respondent received a 
separate questionnaire including questions on the hospital's characteristics, and 11 questions related to the available QA strategies for DCSS at each hospital. The questionnaire was self-administered, and sent out to the responsible persons for QA activities at the DCSS units and returned by mail. Respondents were contacted to address any issues observed.

\section{Study Population}

The questionnaire was distributed in 130 (out of 850) general and specialized hospitals across Iran, which were selected based on purposive sampling. We aimed to have a representative sample of all types of hospitals in our study selecting 130 hospitals based on the hospitals willingness and eligibility for our study. Participation in the survey was voluntary. We received 98 questionnaires from the hospitals (response rate of $75 \%$ ). The received questionnaires were assessed for completeness and consistency. Fourteen questionnaires were excluded from the final analysis due to incompleteness or inconsistency, resulting in a final population of 84 hospitals.

The study population comprised mainly university governmental and SSO hospitals, which all achieved an acceptable grade provided by the government as part of the annual hospital performance grading system. This system consists of a 6 level grading scale from the best performer 'excellent 1', '1', '2,' '3', '4 or substandard' to worst performer ' 5 or to be shut down.' ${ }^{19}$ Four hospitals included in our study obtained the highest grade, and only 1 hospital the lowest acceptable grade (' 3 '). A subgroup of participating hospitals was also involved in teaching activities besides their therapeutic activities. A small minority of hospitals was conducting research besides their therapeutic and teaching activities (Table 1).

\section{Results}

The Diagnostic and Clinical Support Services in Iranian Hospitals

More than $96 \%$ of hospitals reported to have a clinical chemistry laboratory $(n=81)$, diagnostic radiology $(n=82)$, and pharmacy services $(n=84)$ in place. In contrast, only 4 (5\%) hospitals reported having human tissue bank service. Other services that were not very frequently reported to be available were radiotherapy (12\%), magnetic resonance imaging (MRI) (13\%), cardiac catheterization (18\%) and nuclear medicine (19\%).

The Extent of Application of Quality Assurance Strategies Table 2 summarizes the results of the extent of reported application of QA strategies in the DCSS units of hospitals. The results show that almost all QA strategies were reported to be used by the majority of hospitals, though some more than others. Most frequently reported strategies were having a procedure for checking the expiration dates of drugs (94\%) and pharmacopoeia (92\%) in pharmacies, equipment calibration (87\%), and identification of responsibilities (86\%). The least reported strategy was external audit of the services (average: 57\%).

In addition, the following figures illustrate the extent of application of each QA strategies in different DCSS units (Figure).

The Association Between the Application of Quality Assurance in the Diagnostic and Clinical Support Services Units and Hospital Characteristics

There is no significant difference between the reported application rate of QA strategies in DCSS in general and specialized hospitals, with the exception of pharmacies. The pharmacies in the general hospitals reported having a written QA plan significantly more often available than specialized hospitals (on average $70 \%$ compared to $33.3 \%, P=.014$ ). Hospital's ownership type was a relevant feature for the application of QA strategies by pharmacies, radiology units, laboratories (clinical chemistry, microbiology and pathology), MRI, and blood bank units. These units reported applying QA strategies in the SSO's hospitals significantly more often than the units in the university hospitals. This was also the case for the vast majority of QA strategies in the private-for-profit and nonprofit hospitals where they reported the application of QA strategies more often than university hospitals. The only exception was the identification of responsibilities, which did not differ by ownership type, as shown in Table 3 .

There was no significant difference in the reported application rate of QA strategies in the DCSS units in the therapeutic hospitals and the hospitals that were involved in teaching and research activities alongside their therapeutic activities. The only exception was the significantly higher reported

Table 1. Characteristics of the Study Population

\begin{tabular}{|c|c|c|c|c|c|c|c|c|}
\hline \multicolumn{9}{|c|}{ The Number of Hospitals Included by Their Ownership, Type, Annual Evaluation Grade and Teaching Status, n (\%) } \\
\hline \multirow{2}{*}{$\begin{array}{l}\text { Ownership, } \\
\text { n (\%) }\end{array}$} & \multirow{2}{*}{$\begin{array}{l}\text { Type, } \\
\text { n (\%) }\end{array}$} & \multicolumn{4}{|c|}{ Annual Evaluation Grade, n (\%) } & \multicolumn{3}{|c|}{ Teaching Status, $\mathbf{n}(\%)$} \\
\hline & & Excellent 1 & 1 & 2 & 3 & Therapeutic & $\begin{array}{c}\text { Therapeutic }+ \\
\text { Teaching } \\
\end{array}$ & $\begin{array}{c}\text { Therapeutic + Teaching } \\
\text { + Research }\end{array}$ \\
\hline \multirow{2}{*}{$\begin{array}{l}\text { University- } \\
\text { governmental } \\
46(55)\end{array}$} & General, 35 (76) & - & $30(91)$ & $2(6)$ & $1(3)$ & $9(26)$ & $23(66)$ & $3(8)$ \\
\hline & Specialty or subspecialty, $11(24)$ & - & $11(100)$ & - & - & - & $8(73)$ & $3(27)$ \\
\hline \multirow[t]{2}{*}{ SSO, 21 (25) } & General, 21 (100) & $3(14)$ & $17(81)$ & $1(5)$ & - & $12(57)$ & $9(43)$ & - \\
\hline & Specialty or subspecialty & - & - & - & - & - & - & - \\
\hline \multirow{2}{*}{$\begin{array}{l}\text { Private-for- } \\
\text { profit, } 12(14)\end{array}$} & General, 11 (92) & $1(10)$ & $8(80)$ & $1(10)$ & - & $11(100)$ & - & - \\
\hline & Specialty or subspecialty, 1 (8) & - & $1(100)$ & - & - & - & - & - \\
\hline \multirow{2}{*}{$\begin{array}{l}\text { Private } \\
\text { nonprofit, } 5 \text { (6) }\end{array}$} & General, 5 (100) & - & $4(80)$ & $1(20)$ & - & $3(60)$ & $1(20)$ & $1(20)$ \\
\hline & Specialty or subspecialty & - & - & - & - & - & - & - \\
\hline
\end{tabular}

Abbreviation: SSO, Social Security Organization. 


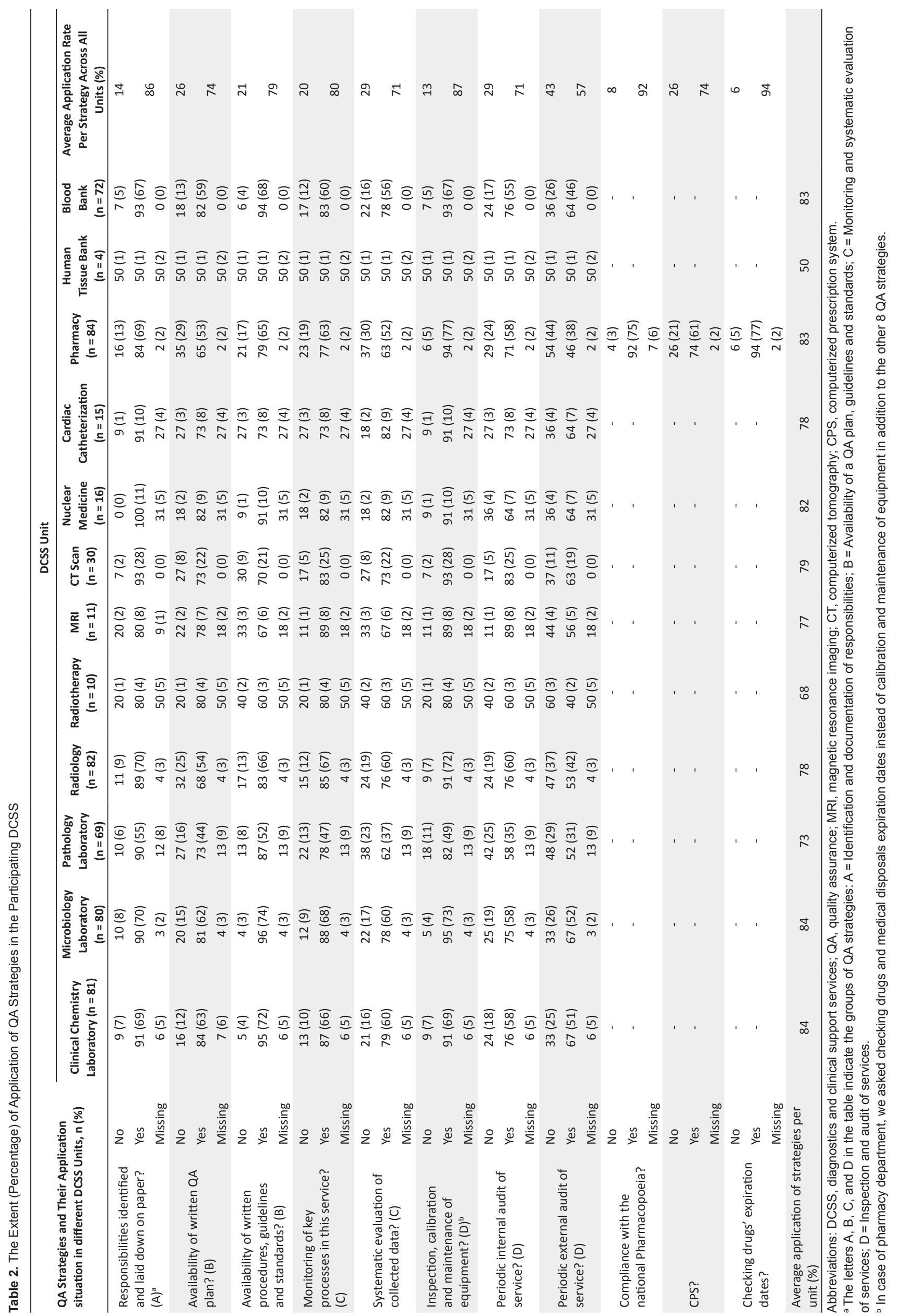



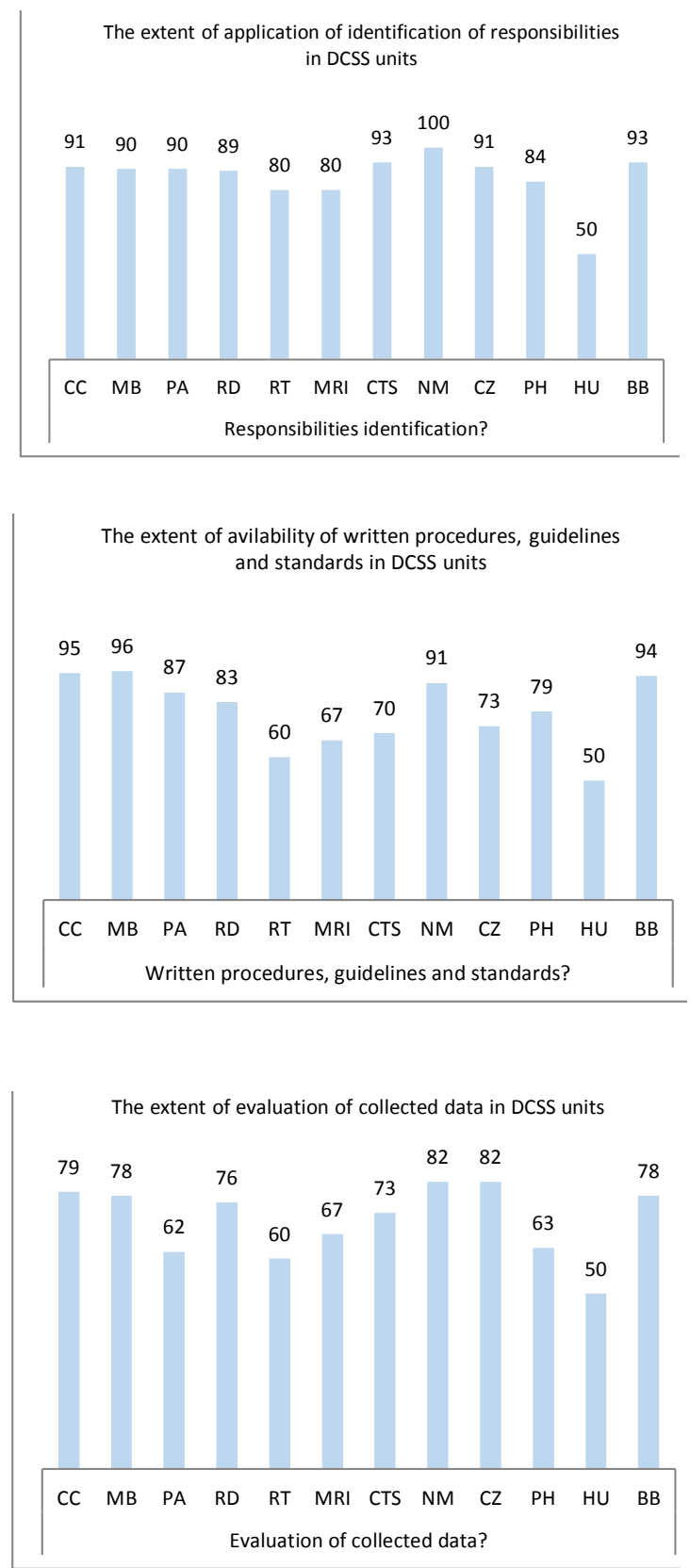

The extent of application of internal audit in DCSS units

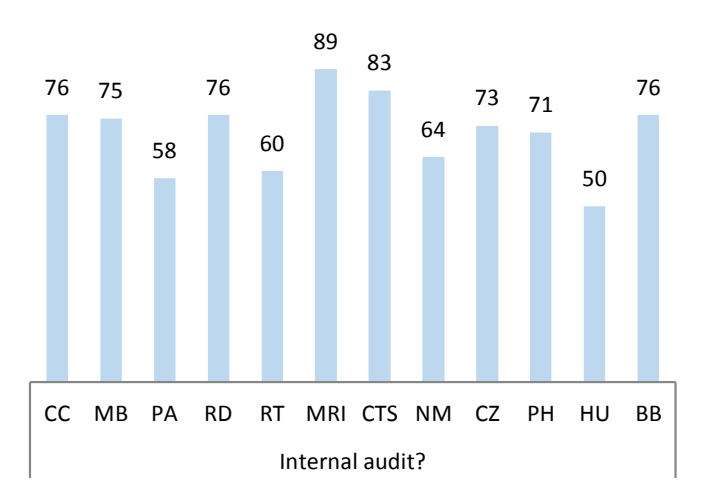

The extent of avilability of written QA plan in DCSS units

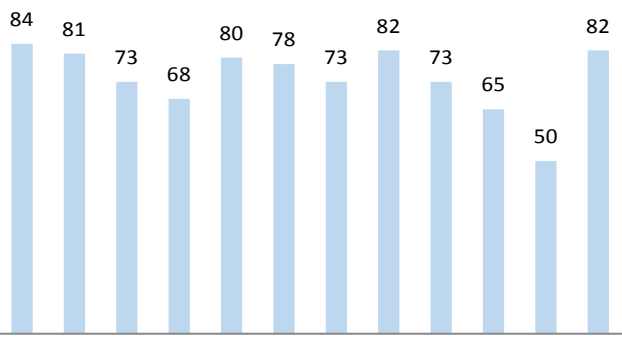

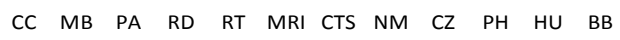
Availability of QA plan?

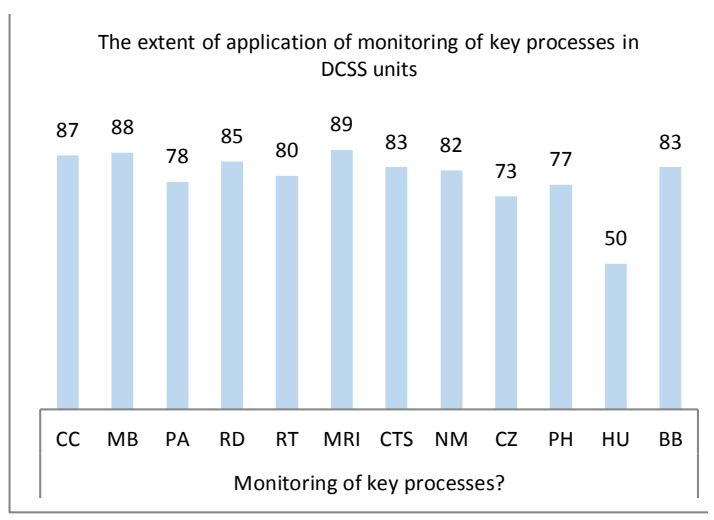

The extent of application of inspection, calibration, and maintenance in DCSS units

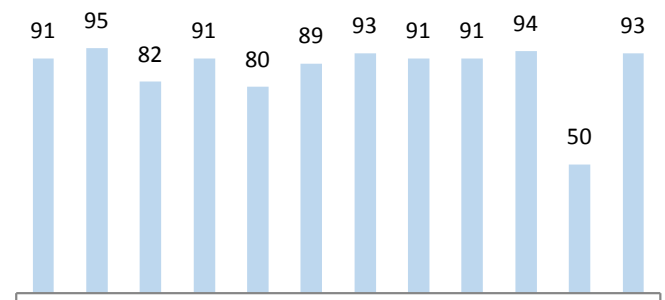

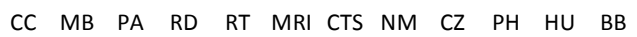
Inspection, calibration, and maintenance?

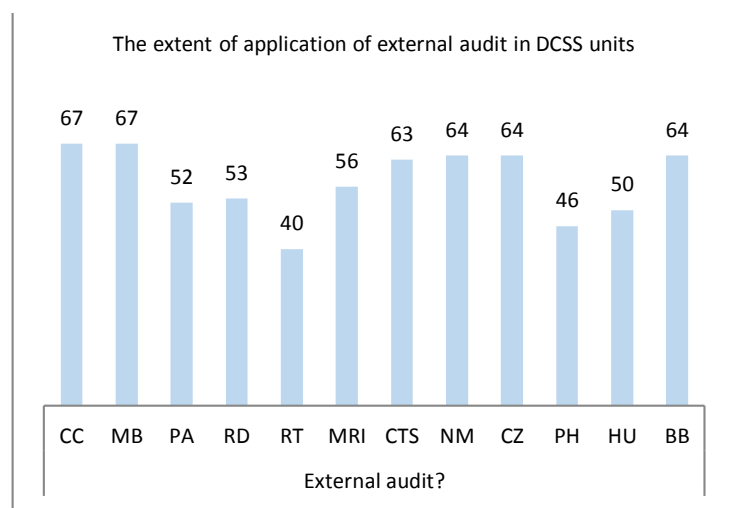

Figure. The Extent of Application of QA Strategies in the Participating DCSS Units. Abbreviations: CC, clinical chemistry laboratory; MB, microbiology laboratory; PA, pathology laboratory; RD, radiology; RT, radiotherapy; MRI, magnetic resonance imaging; CTS, computerized tomography scan; NM, nuclear medicine; CZ, cardiac catheterization; PH, pharmacy; HU, human tissue bank; BB, blood bank; DCSS, diagnostics and clinical support services; QA, quality assurance. 
Table 3. The Associations Between the Extent of Application of QA Strategies in DCSS units and Ownership of Hospitals

\begin{tabular}{|c|c|c|c|c|c|c|c|}
\hline \multirow[t]{2}{*}{ QA Strategies Category } & \multirow[t]{2}{*}{ QA Strategies Subgroups } & \multirow[t]{2}{*}{ DCSS Unit } & \multicolumn{4}{|c|}{$\begin{array}{c}\text { The Application Rate of Strategy by } \\
\text { the Ownership of Hospitals (\%) }\end{array}$} & \multirow[t]{2}{*}{$P$} \\
\hline & & & University & SSO & PFP & PNP & \\
\hline $\begin{array}{l}\text { A) Identification of } \\
\text { responsibilities }\end{array}$ & $\begin{array}{l}\text { Responsibilities identified and laid } \\
\text { down on paper? }\end{array}$ & & & & & & \\
\hline \multirow{3}{*}{$\begin{array}{l}\text { B) Availability of QA plan, } \\
\text { guidelines and standards }\end{array}$} & \multirow{2}{*}{ Availability of written QA plan? } & Pharmacy & 53.3 & 95.0 & 58.3 & 60 & .013 \\
\hline & & Radiology & 53.5 & 95.2 & 80.0 & 60 & .007 \\
\hline & $\begin{array}{l}\text { Availability of written procedures, } \\
\text { guidelines and standards? }\end{array}$ & Pharmacy & 66.7 & 100 & 100 & 60 & .003 \\
\hline \multirow{5}{*}{$\begin{array}{l}\text { C) Monitoring and systematic } \\
\text { evaluation of service }\end{array}$} & \multirow{3}{*}{$\begin{array}{l}\text { Monitoring of key processes in this } \\
\text { service? }\end{array}$} & Clinical chemistry laboratory & 75.5 & 100 & 100 & 100 & .020 \\
\hline & & Microbiology laboratory & 78.6 & 100 & 100 & 100 & .037 \\
\hline & & Pharmacy & 62.2 & 95.0 & 100 & 80 & .005 \\
\hline & \multirow{2}{*}{$\begin{array}{l}\text { Systematic evaluation of collected } \\
\text { data? }\end{array}$} & Pathology laboratory & 47.1 & 75.0 & 77.8 & 100 & .045 \\
\hline & & Pharmacy & 51.1 & 95.0 & 75.0 & 20 & .001 \\
\hline \multirow{12}{*}{$\begin{array}{l}\text { D) Inspection and audit of } \\
\text { service }\end{array}$} & \multirow{3}{*}{$\begin{array}{l}\text { Inspection, calibration and } \\
\text { maintenance of equipment? }\end{array}$} & Clinical chemistry laboratory & 87.8 & 100 & 100 & 60 & .027 \\
\hline & & Radiology & 90.7 & 100 & 90.0 & 60 & .045 \\
\hline & & MRI & 100 & 100 & 100 & 0 & .029 \\
\hline & \multirow{4}{*}{ Periodic internal audit of service? } & Pathology laboratory & 38.2 & 75.0 & 100 & 80 & .002 \\
\hline & & Microbiology laboratory & 61.9 & 84.2 & 100 & 100 & .018 \\
\hline & & Pharmacy & 60.0 & 95.0 & 75.0 & 60 & .035 \\
\hline & & Radiology & 65.1 & 95.2 & 90.0 & 60 & .032 \\
\hline & \multirow{5}{*}{ Periodic external audit of service? } & Clinical chemistry laboratory & 53.7 & 100 & 72.7 & 40 & .002 \\
\hline & & Microbiology laboratory & 54.8 & 100 & 72.7 & 40 & .003 \\
\hline & & Blood bank & 48.7 & 89.5 & 80.0 & 50 & .013 \\
\hline & & Pharmacy & 31.1 & 90.0 & 50.0 & 0 & .000 \\
\hline & & Radiology & 37.2 & 95.2 & 50.0 & 20 & .000 \\
\hline
\end{tabular}

Abbreviations: DCSS, diagnostics and clinical support services; QA, quality assurance; MRI, magnetic resonance imaging; SSO, Social Security Organization; PFP, private-for-profit; PNP, private nonprofit.

availability of a written QA plan in the radiology departments in the hospitals which were involved in research activities besides their therapeutic and teaching activities $(P=.036)$. The availability of a written QA plan in the therapeutic, therapeutic/teaching, and therapeutic/teaching/research hospitals were reported by $75.8 \%, 56.4 \%$ and $100 \%$ of the hospitals, respectively.

The radiology, MRI, computerized tomography (CT) scan, nuclear medicine and radiotherapy departments in the hospitals with different annual performance evaluation grades were significantly different in the reported identification of responsibilities, availability of a written QA plan, monitoring of key processes and systematic evaluation of collected data strategies as shown in Table 4.

The identification of responsibilities (except in the radiology departments), availability of a written QA plan, monitoring of key processes and systematic evaluation of collected data in the radiology, MRI, CT scan, nuclear medicine and radiotherapy departments were significantly more often reported in the grade 1 hospitals compared to the excellent 1 hospitals.

There is no significant difference between the reported application rate of having pharmacopoeia and a CPS available, and checking drugs expiration dates in the pharmacies in different (general/specialized and teaching/nonteaching) hospitals.

\section{Discussion}

We studied the extent of application of 4 groups of QA strategies (representing the managerial cycle) by inpatient DCSS units and its association with the key characteristics of
Iranian hospitals. To our best knowledge, this is the first study that explores the application of specific QA strategies in the DCSS units in Iranian hospitals. However, the study has some limitations concerning the sample size and composition of the study population. First of all, the study is limited to the DCSS units that are located within Iranian hospitals excluding DCSS in outpatient units. Because of time and financial limitations we were not able to expand our study sample to the DCSS units outside of hospitals. Moreover, the DCSS units outside of hospitals are mostly part of the private sector in Iran. As a result, they are not statutorily obliged to participate in research. Secondly, the study population included a relatively small number of specialized DCSS units such as human tissue bank or radiotherapy departments compared to the total number of DCSS units in Iran, which is a reflection of the relatively small number of available specialized DCSS units across the country. Nevertheless, we belief our study provides a good indication of the current state of affairs concerning the use of QA strategies by DCSS units in hospitals. Finally, the use of a purposive sampling method and a self-reported questionnaire in this study might have led to some biases in the results. For instance, respondents may be more likely to report a better performance in application of QA strategies. To minimize the possible biases because of purposive sampling, we checked all data on any inconsistencies and uncertainties. We conducted follow up conversations with respondents for any identified uncertain and unclear data and excluded data which were unlikely based on our experiences.

Our study revealed that all strategies were reported to be widely used (ranging 57\%-94\%) by the DCSS. Most frequently reported strategies were checking the expiration date of drugs 
Table 4. The Associations Between the Extent of Application of QA Strategies in DCSS Units and Hospital Annual Evaluation Grade

\begin{tabular}{|c|c|c|c|c|c|c|c|}
\hline \multirow{2}{*}{ QA Strategies Category } & \multirow{2}{*}{ QA Strategies Subgroups } & \multirow{2}{*}{ DCSS Unit } & \multicolumn{4}{|c|}{$\begin{array}{l}\text { The extent of application rate of strategy by } \\
\text { the grade of hospitals }\end{array}$} & \multirow{2}{*}{$\boldsymbol{P}$} \\
\hline & & & $\begin{array}{c}\text { Excellent } 1 \\
\text { (Best) }\end{array}$ & Grade 1 & Grade 2 & $\begin{array}{l}\text { Grade } 3 \\
\text { (Worst) }\end{array}$ & \\
\hline \multirow{3}{*}{$\begin{array}{l}\text { Identification of } \\
\text { responsibilities }\end{array}$} & \multirow{3}{*}{$\begin{array}{l}\text { Responsibilities identified and laid down } \\
\text { on paper? }\end{array}$} & Radiology & 100 & 89.9 & 50 & - & .041 \\
\hline & & MRI & 0 & 89.9 & - & - & .035 \\
\hline & & CT scan & 50 & 96.3 & 0 & - & .039 \\
\hline \multirow{4}{*}{$\begin{array}{l}\text { Availability of QA plan, } \\
\text { guidelines and standards }\end{array}$} & \multirow{3}{*}{ Availability of written QA plan? } & MRI & 0 & 87.5 & - & - & .047 \\
\hline & & Nuclear medicine & 0 & 90.0 & - & - & .026 \\
\hline & & Radiology & 0 & 100 & - & - & .025 \\
\hline & $\begin{array}{l}\text { Availability of written procedures, } \\
\text { guidelines and standards? }\end{array}$ & - & - & - & - & - & - \\
\hline \multirow{4}{*}{$\begin{array}{l}\text { Monitoring and systematic } \\
\text { evaluation of service }\end{array}$} & \multirow{3}{*}{$\begin{array}{l}\text { Monitoring of key processes in this } \\
\text { service? }\end{array}$} & MRI & 0 & 100 & - & - & .003 \\
\hline & & Nuclear medicine & 0 & 90.0 & - & - & .026 \\
\hline & & Radiotherapy & 0 & 100 & - & - & .025 \\
\hline & Systematic evaluation of collected data? & Nuclear medicine & 0 & 90.0 & - & - & .026 \\
\hline \multirow{3}{*}{$\begin{array}{l}\text { Inspection and audit of } \\
\text { service }\end{array}$} & $\begin{array}{l}\text { Inspection, calibration and maintenance } \\
\text { of equipment? }\end{array}$ & - & - & - & - & - & - \\
\hline & Periodic internal audit of service? & - & - & - & - & - & - \\
\hline & Periodic external audit of service? & - & - & - & - & - & - \\
\hline
\end{tabular}

Abbreviations: DCSS, diagnostics and clinical support services; QA, quality assurance; MRI, magnetic resonance imaging; CT, computerized tomography.

and having a pharmacopoeia, equipment calibration, and identification/outline of responsibilities. Particularly QA strategies that are directly linked to the safety of patients in DCSS units, were reported to be highly applied. The least reported strategy was the performance of external audits of the services by an accreditation or certification institute. The results also showed that there was no significant association between the reported application rates of QA strategies in DCSS (with the exception of the availability of a written QA plan) and the hospital type and teaching status of hospitals. The reported application rates of all QA strategies (with the exception of identification of responsibilities) in the clinical chemistry, microbiology and pathology laboratories, pharmacy, radiology, MRI and blood bank departments appear to be associated with the ownership type of hospitals, which was reported significantly higher in the SSO's hospitals compared to the other hospitals. It seems the implementation of total quality management (TQM) systems based on ISO standards was the main factor in successful application of QA strategies in the DCSS units at the SSO hospitals. ${ }^{19}$ Moreover, the application of identification of responsibilities, availability of written QA plan, monitoring of key processes and systematic evaluation of collected data strategies in the radiology, MRI, CT scan, nuclear medicine and radiotherapy departments were associated to the annual performance evaluation grade of the hospitals. These findings were to a great extent also confirmed by other studies in this field. ${ }^{24}$

From Formalization and Standardization of Quality Assurance Strategies Toward Feedback and Improvement

Although the majority of the QA strategies examined in this study were reported to be widely applied by DCSS units, emphasis seems to be on formalization and standardization rather than on feedback and improvement. The first steps of the management cycle (formalization and standardization) are reported to be covered but reports on actual closing the loop through feedback and change and hence institutionalized continuous quality control and improvement seem less common. This is also confirmed by other studies in Iranian hospitals. ${ }^{21,25}$ Particularly the application of QA strategies such as external and internal audits in most DCSS units, or CPS in the pharmacies seem in need of strengthening towards further completing the managerial cycle for QA in hospitals. Audit is one of the main strategies to monitor and improve the quality of the DCSS units. ${ }^{11,26}$ Furthermore, audits are necessary to identify the main concerns of the clinical performance of DCSS services for patients, receive feedback, change and learning. ${ }^{27}$ Despite having a potential critical role in improving quality of clinical care, the application of audits is not being reported sufficiently in some DCSS units (such as radiology, radiotherapy, laboratory, pharmacy and blood bank) particularly in the university and nonprofit hospitals. In general, it seems there are some potential barriers in the execution of audits not only in DCSS units, but across the hospital sector in Iran. It might be as consequence of the execution of the annual performance evaluation in the DCSS units in Iranian hospitals. This might cause misunderstanding that the internal audits of the DCSS services at specific units are not necessary. Another barrier might be the reluctance of the hospitals and relevant departments to be controlled for quality initiatives.

Regarding the application of QA strategies in pharmacies, nearly all pharmacies reported to have a pharmacopoeia, and a procedure for checking the expiration dates of drugs before providing them to patients. However, the application of some of the QA strategies (eg, CPS) should be improved in pharmacies. The impact of these strategies in QA in pharmacies has also been reported by other studies in this field. ${ }^{15}$ Our study shows that only around three-fourths of pharmacies have a CPS in place. Although this may appear sufficiently high, there are still many reported adverse events in Iran due to medication errors that can be prevented using CPS. ${ }^{28}$ The effective application of the CPS as one of the main QA strategies in pharmacies might help decrease the 
medication errors.

Improving the Effectiveness of Quality Assurance Strategies in the Diagnostic and Clinical Support Services Units

Despite the relatively high average application rates reported for the majority of the QA strategies in the DCSS units (as shown in Table 2), the statistics in medical and diagnostic errors cause concern for healthcare policy-makers as they may point to potential hazardous diagnostic and clinical support services in Iranian hospitals. Although there are no reliable statistics available on this matter in DCSS units, it has been reported that a large number of people experience adverse events every year due to medication and diagnostic errors, substandard treatments and poor clinical support services in Iran. ${ }^{28}$ An estimated 24500 people die each year due to medical and diagnostic errors in Iran. In addition, the prevalence of hospital acquired infections is reported as high as $8 \%-10 \%$ of admitted patients in Iranian hospitals. ${ }^{24}$ This is a global health problem as many healthcare systems are still faced with medical and diagnostic errors. Nevertheless, these problems partly would be manageable by improving the effectiveness in medical and clinical services using effective strategies through QA approaches and increase the accountability of hospitals including DCSS units. This leaves the debate open for the real impact of the application of QA strategies in the DCSS units in practice. It seems there is still a remarkable difference between the reported application rate of QA strategies in DCSS units and their impact on quality of care. It might be because the QA strategies are not being applied sufficiently effective in the DCSS units. Improvement of the organizational responsiveness and internal use of quality outcomes for quality improvement purposes, feedback systems and sharing the results, quality improvement, learning and creation of a quality culture in the DCSS units may increase the effectiveness of strategies and complete the managerial cycle of QA in these units. ${ }^{24,25}$ This will likely improve the internal and external accountability of hospitals and consequently the DCSS units.

A Balance in Applying Quality Assurance Strategies in the Diagnostic and Clinical Support Services Both in Inpatient and Outpatient Units

Our study showed that the QA strategies are widely reported in the DCSS units located inside hospitals, probably partly because of the existence of QA monitoring systems which are applied to all inpatient units within hospitals. According to the healthcare regulations in Iran, the diagnostic and clinical support services that are located within hospitals should undergo particular scheduled and routine programs assisting QA compliance. ${ }^{19}$ Therefore, the compliance with the application of some QA strategies (eg, written guidelines and standards) are checked in the annual performance evaluation process which is also obligatory for the DCSS units located within the hospitals and may increase the level of compliances by these units located. Although we did not study the application status in outpatient units, it is known that they are not obliged to apply QA strategies except for clinical laboratories (need to implement national quality standards adapted from ISO 15189 standards since few years ago). ${ }^{14,29}$ This underscores the need for close attention to the application of the strategies in outpatient DCSS units to increase the compliance with national QA requirements.

\section{Conclusion}

Although QA strategies seem to be adequately applied in most inpatient DCSS units of Iranian hospitals, getting feedback, implementing changes and learning need to be improved to complete the managerial cycle of the QA system. Given the high reported percentage of application of QA strategies, the DCSS in Iranian hospitals demonstrate at least a keen awareness of quality issues. However, there are concerns about the relatively low application of some specific strategies including the audits in some DCSS units and CPS in pharmacies. Execution of the audit programs in DCSS units may help these units to really improve their level of quality. This can be achieved by statutorily incorporation of audit programs in the hospital performance evaluation program and using the results for internal hospital quality improvement processes in hospitals including DCSS units. Moreover, the effectiveness of QA strategies in practice in inpatient DCSS units needs to be improved, given the gap in the reported QA application rates, adverse events and complications. The magnitude of the reported problems in hospitals ask for action to further increase the effectiveness QA strategies and their use for both internal accountability (quality improvement actions) of DCSS units in addition to external accountability purposes. It is also recommended to pay more attention to QA strategies in outpatient DCSS units, given the current policy attention of the Iranian government on inpatient settings.

\begin{abstract}
Ethical issues
The study was approved by the Deputy of Research and Technology of the Iran University of Medical Sciences, Tehran, Iran (code: 958/1635996). The
\end{abstract} manuscript does not contain clinical studies or patient data.

Competing interests

The authors declare that they have no competing interests.

\section{Authors' contributions}

$\mathrm{AAH}$ designed the study, prepared the questionnaire, collected the data, performed the data analysis, and drafted the manuscript. DK provided support in the data analysis, edited the English text, and contributed to writing the manuscript. HR, JM and, HAG facilitated the data collection in Iran, provided advice on the study design and commented on drafts of the manuscript. NSK coordinated the study, provided advice on all stages of the study, and contributed to drafting the manuscript. All authors read and approved the final manuscript.

\section{Authors' affiliations}

${ }^{1}$ Department of Public Health, Academic Medical Center (AMC), University of Amsterdam (UvA), Amsterdam, The Netherlands. ${ }^{2}$ Department of Health Services Management, School of Health Services Management and Information Sciences, Iran University of Medical Sciences, Tehran, Iran. ${ }^{3}$ Department of Quality Improvement, Tehran Heart Center Hospital, Tehran, Iran.

\section{References}

1. Peeling RW, Smith PG, Bossuyt PM. A guide for diagnostic evaluations. Nat Rev Microbiol. 2010;8(12)S2-S6. doi:10.1038/ nrmicro1522

2. The free dictionary website. http://medical-dictionary. thefreedictionary.com/clinical+support+service. 
March 7, 2014.

3. Dubois RW, Brook RH. Preventable deaths: who, how often, and why? Ann Intern Med. 1988;109(7):582-589. doi:10.7326/00034819-109-7-582

4. Brook RH, Kamberg CJ, Mayer-Oakes A, Beers MH, Raube K, Steiner A. Appropriateness of acute medical care for the elderly: an analysis of the literature. Health Policy 1990;14(3):225-242. doi:10.1016/0168-8510(90)90037-e

5. Leape LL. Error in medicine. JAMA. 1994;272(23):1851-1857. doi:10.1001/jama.272.23.1851

6. Institute of Medicine (IOM). To Err Is Human. Washington DC: National Academy Press; 2000.

7. Quality assurance of laboratory test results at the medical research institute. http://www.mri.gov.lk/en/news/quality-assurance-oflaboratory-test-results-at-the-medical-research-institute-wemaintain-quality-and-others-to-follow/. Accessed July 20, 2013.

8. Patient safety. World Health Organization website. http://www. emro.who.int/entity/patient-safety. Accessed June 7, 2013.

9. Newman-Toker DE, Pronovost PJ. Diagnostic errors-the next frontier for patient safety. JAMA 2009;301:1060-1062. doi:10.1001/jama.2009.249

10. World Health Organization (WHO). Quality Assurance in Health Laboratory Services: A Status Report. New Delhi: World Health Organization, Regional Office for South-East Asia; 2003.

11. Quality Control in a Virology Laboratory. http://virology-online. com/general/QualityControl.htm. Accessed July 13, 2014.

12. 10 facts on Patient Safety. World Health Organization website. http://www.who.int/features/factfiles/patient_safety/en/. Accessed January 6, 2014.

13. Hajia M, Safadel N, Mirab Samiee S, et al. Quality Assurance Program for Molecular Medicine Laboratories. Iran J Public Health. 2013;42(Supple1):119-124.

14. Safadel N, Dahim P, Anjarani S, et al. Challenges of implementing iranian national laboratory standards. Iran J Public Health. 2013;42:125-128.

15. Dargahi H, Khosravi SH. Hospitals pharmacy quality assurance system assessment in Tehran University of Medical Sciences, Iran. Iran J Public Health. 2010;39(4):102-113.

16. Ministry of Health and Medical Education (MoHME). The act of the Islamic Republic of Iran's Parliament on National Health. Tehran: MoHME; 1995.

17. Regional Health Systems Observatory- EMRO, Health Systems Profile- Islamic Republic of Iran, 2006. World Health Organization website. http://gis.emro.who.int/HealthSystemObservatory/PDF/
Iran/Full\%20Profile.pdf. Accessed May 2, 2014.

18. Iranian Blood Transfusion Organization (IBTO) website. http:// www.ibto.ir/HomePage. aspx?Lang=en-US\&site=ibto\&tabid=1 . Accessed February 25, 2014.

19. Aghaei Hashjin A, Delgoshaei B, Kringos DS, Tabibi SJ, Manoochehri J, Klazinga NS. Implementation of hospital quality assurance policies in Iran: balancing the role of licensing, annual evaluation, inspections and quality management systems. Int J Health Care Qual Assur. 2015;28(4):1-15. doi:10.1108/ IJHCQA-03-2014-0034

20. The Inter-country Workshop on Quality Assurance of Laboratory Diagnosis for Malaria, Tehran, Islamic Republic of Iran, 2001. World Health Organization. http://applications.emro.who.int/ docs/who_em_mal_269_e_I_en.pdf

21. Hospital wide quality assurance, NEC Healthcare Display Solutions, Featuring GammaCompMD QA with QAXRAY Module. http://www.nec-display-solutions.com. Accessed October 3, 2013.

22. Marquis project. http://www.marquis.be. Accessed November 10, 2007.

23. Marquis questionnaire. Available from: http://www.marquis.be. Accessed November 15, 2007.

24. Aghaei Hashjin A, Kringos DS, Manoochehri J, Ravaghi $\mathrm{H}$, Klazinga NS. Implementation of patient safety and patientcenteredness strategies in Iranian hospitals. PLoS One. 2014;9(9):e108831. doi:10.1371/journal.pone.0108831

25. Aghaei Hashjin A, Ravaghi H, Kringos DS, et al. Using Quality Measures for Quality Improvement: The Perspective of Hospital Staff. PLoS One. 2014;9(1):e86014. doi:10.1371/journal. pone. 0086014

26. Monograph on the internet. Anonymous Encouraging pharmacy staff to develop their audit and research skills pays dividends, 2009. http://www.pharmacy.org.uk.

27. Ronsmans $\mathrm{C}$. What is the evidence for the role of audits to improve the quality of obstetric care. http://www.jsieurope.org/ safem/collect/safem/pdf/s2939e/s2939e.pdf. Accessed March 6, 2014.

28. Zargarzadeh AH. Medication Safety in Iran. J Pharm Care 2013;1(4):125-126.

29. Ravaghi H, Abolhassani N, Dahim P, Shaarbafchi N, Anjarani $\mathrm{N}$, Safadel N. Assessors' attitudes toward and experiences of national quality standards: a qualitative study in Iran. Accred Qual Assur. 2014;19:301-305. doi:10.1007/s00769-014-1060-9 